\title{
Interpersonal Sensitivity Mediates the Effects of
} Childhood Maltreatment on the Evaluation of Life

\section{Events and Anxiety States in Adult Community Volunteers}

\author{
Hiroshi Nakazawa (iD) \\ Jiro Masuya' \\ Hajime Tanabe ${ }^{2}$ \\ Ichiro Kusumi $\mathbb{D D}^{3}$ \\ Takeshi Inoue (D) \\ Masahiko Ichiki' \\ 'Department of Psychiatry, Tokyo \\ Medical University, Shinjuku-ku, Tokyo, \\ 160-0023, Japan; ${ }^{2}$ Faculty of Humanities \\ and Social Sciences, Shizuoka University, \\ Suruga-ku, Shizuoka, 422-8529, Japan; \\ ${ }^{3}$ Department of Psychiatry, Hokkaido \\ University Graduate School of Medicine, \\ Kita-ku, Sapporo, 060-8638, Japan
}

Correspondence: Takeshi Inoue

Department of Psychiatry, Tokyo Medical University, 6-7-I Nishishinjuku, Shinjukuku, Tokyo, 160-0023, Japan

Tel +8I $33342611 \mathrm{I}$

Fax +8I 333404499

Email tinoue@tokyo-med.ac.jp
Background: Childhood maltreatment has long-lasting psychological effects, which often manifest in adulthood. Previous studies have suggested that the effects of childhood maltreatment are not only direct but also indirect, being mediated by other factors. In this study, we hypothesized that the effects of childhood maltreatment on state anxiety in adulthood are mediated by interpersonal sensitivity and the evaluation of life events, and investigated this possibility by covariance structure analysis.

Subjects and Methods: Self-administered questionnaires (Child Abuse and Trauma Scale, State-Trait Anxiety Inventory Form Y, Life Experiences Survey, and Interpersonal Sensitivity Measure) were distributed to adult community volunteers in Japan, and 404 eligible responses were collected. A structural equation model was constructed to analyze the direct and indirect effects of childhood maltreatment on state anxiety, with interpersonal sensitivity and the evaluation of life events as potential mediators.

Results: Our model showed that childhood maltreatment increases state anxiety in adulthood both directly and indirectly via interpersonal sensitivity. In addition, interpersonal sensitivity mediated the effects of childhood maltreatment on the negative evaluation of life events, and the negative evaluation of life events mediated the effects of interpersonal sensitivity on anxiety symptoms.

Limitations: There may be possible recall bias owing to the self-administration of the questionnaire. In addition, this study had a cross-sectional design, and hence the results should be validated by a prospective study.

Conclusion: The effects of childhood maltreatment on the state anxiety of adult volunteers are not only direct but are also mediated by interpersonal sensitivity. Our results suggest that assessing interpersonal sensitivity may help to determine optimal treatments for patients with anxiety who experienced maltreatment in childhood.

Keywords: covariance structure analysis, child abuse and trauma scale, state-trait anxiety inventory form $\mathrm{Y}$, interpersonal sensitivity measure, life experiences survey

\section{Introduction}

The experience of maltreatment in childhood is known to seriously affect mental health, as it is associated with disabilities, such as depression, self-injury, and suicidality. ${ }^{1}$ Childhood maltreatment has been suggested to cause neurobiological changes, including abnormalities of the hypothalamic-pituitary-adrenal axis and 
hypofunction of the hippocampus, and psychological changes, such as effects on sensory perception in emotional processes. ${ }^{2,3}$ Furthermore, several previous studies have analyzed the association between childhood maltreatment and the development of anxiety disorders and anxiety symptoms in adulthood. The prevalence of anxiety disorder without comorbidities is known to be higher in individuals who have experienced childhood maltreatment than in those who have not. ${ }^{4} \mathrm{~A}$ meta-analysis demonstrated that a history of sexual or physical abuse in childhood is associated with anxiety, ${ }^{5}$ and similarly, the association between childhood maltreatment and anxiety was reported in a meta-analysis of longitudinal studies of children with a documented history of childhood maltreatment. ${ }^{6}$ Although there is a substantial interval between the time of childhood maltreatment and the development of state anxiety in adulthood, a study on women with a history of sexual abuse or other repeated abuse who were followed for 25 years reported that such women had a higher prevalence of mental disorders, such as anxiety disorders, even at the age of 50 years or older compared with women with no history of abuse. ${ }^{7}$ Furthermore, in individuals who were 65 years or older, even after adjusting for comorbidities, socioeconomic status, and psychiatric treatment, the prevalence of anxiety disorders was higher in those who had experienced childhood maltreatment than in those who had not. ${ }^{8}$ These results hence demonstrated that the experience of childhood maltreatment affects the prevalence of anxiety disorders even in individuals older than 50 years of age.

Rapsey et al suggested that the clinical mechanism of the long-term effects of childhood maltreatment is not only direct but also occurs through some mediating factors. ${ }^{7}$ In a study of adult patients with depression, inappropriate emotional control was found to mediate the effects of childhood maltreatment on anxiety symptoms. ${ }^{9}$ A study of women who had experienced abuse in childhood also demonstrated that the effects of sexual abuse on present anxiety symptoms were mediated by maladaptive behaviors that developed during childhood. ${ }^{10} \mathrm{~A}$ recent study on victims of sexual abuse reported that negative emotions mediate the effects of repeated abuse and nonsexual abuse on trait anxiety. ${ }^{11}$ Furthermore, Widom et al performed a study on victims of physical abuse and neglect, and reported that anxious adult attachment styles mediated the association between childhood maltreatment and anxiety symptoms. ${ }^{12}$

Whether interpersonal sensitivity as a personality trait mediates the effects of childhood maltreatment on state anxiety is also an important issue. Regarding the association between childhood maltreatment and interpersonal sensitivity, we previously demonstrated that these 2 factors were correlated, by analysis of the adult volunteers. ${ }^{13}$ Regarding the association between interpersonal sensitivity and anxiety, Harb et al investigated interpersonal sensitivity in patients with social anxiety disorder, and found that the social anxiety disorder group had higher interpersonal sensitivity scores than the control group. ${ }^{14}$ However, to our knowledge, no studies have been performed to date on whether interpersonal sensitivity as a personality trait mediates the effects of the experience of childhood maltreatment on state anxiety as an adult.

Sarason et al reported that subjective assessments of the desirability or undesirability of life events are appropriate for evaluating the effects of stressors. ${ }^{15}$ The number of negative event appraisals reportedly increases with the severity of childhood psychological abuse. ${ }^{16}$ Sarason et al developed a method for assessing evaluations of life events, and found that negative life event scores were associated with trait and state anxiety. ${ }^{15}$ A functional magnetic resonance study of women who experienced severe stress in childhood reported that the severity of childhood stress is associated with a decrease in the ability to control the stress response. ${ }^{17}$ Thus, it is possible that childhood maltreatment may also affect stress perception. However, to our knowledge, there are no studies to date on whether the evaluation of life events mediates the effects of childhood maltreatment on state anxiety in adulthood. In addition, a study of social stress in healthy college students reported that under stressed conditions, interpersonal sensitivity is associated with sympathetic tone and increased reactivity to stress. ${ }^{18}$ On the other hand, no studies to date have investigated the mediating effects of interpersonal sensitivity on the effects of childhood maltreatment on the evaluation of life events.

In a previous study of psychological interventions for individuals with a history of childhood maltreatment, Shahar et al reported that the effects of emotional abuse experienced in childhood on symptoms of social anxiety in the nonclinical community participants were mediated by shame and self-criticism, and that these mediators should hence be the target of cognitive behavioral and other psychological therapies. ${ }^{19}$ In fact, interpersonal sensitivity 
as a personality trait was also shown to be moderated by cognitive behavioral therapy. ${ }^{14}$ If interpersonal sensitivity and evaluations of life events mediate the effects of childhood maltreatment on state anxiety, interventions aimed at improving these mediators may have promising therapeutic potential.

In the present study, we hypothesized that interpersonal sensitivity and the evaluation of life events mediate the effects of childhood maltreatment on state anxiety in adulthood. A questionnaire-based survey was administered to adult volunteers in the community, to investigate whether the effects of childhood maltreatment on anxiety symptoms in adulthood are mediated by interpersonal sensitivity and the evaluation of life events, using covariance structure analysis.

\section{Subjects and Methods Subjects}

This study was conducted as part of a larger study performed between January and August, 2014. A questionnaire was distributed to 853 Japanese adult volunteers, and $47.4 \%$ (404 volunteers; 220 men and 184 women) agreed to participate and submitted their responses. ${ }^{13,20-22}$ Inclusion criteria were as follows: (a) at least 20 years of age; (b) no serious physical illness; (c) no organic brain damage; and (d) able to provide informed consent to participate in this research. Exclusion criteria were not set because this study intended to include both healthy subjects and subjects with disorders.

The study was conducted anonymously. The subjects were informed that their participation was of their own free will, there would be no disadvantage by nonparticipation, the data would be processed anonymously, and their personal information would be protected. Their consent to participate was obtained in writing. The Tokyo Medical University Institutional Review Board approved the protocol (study approval no.: SH3308), in accordance with the seventh edition of the Declaration of Helsinki. ${ }^{23}$

\section{Questionnaires}

\section{State-Trait Anxiety Inventory Form Y (STAI-Y)}

The STAI-Y is a 40-item self-administered questionnaire consisting of 20 questions each on state and trait anxiety. ${ }^{24}$ In the present study, only the answers on state anxiety were used for analysis. The Japanese version of this questionnaire, which was developed by Hidano et al, ${ }^{25}$ was used in this study.

\section{Child Abuse and Trauma Scale (CATS)}

The CATS is a 38-item self-administered questionnaire that assesses the experience of maltreatment in childhood and adolescence, ${ }^{26}$ and comprises subscales of neglect, punishment, and sexual abuse. The mean of the total score and score of each subscale was calculated. The Japanese version used in this study was established by Tanabe (2010). ${ }^{27}$

\section{Life Experiences Survey (LES)}

The LES is a self-administered questionnaire that assesses the presence or absence of 57 life events in the previous year, and the intensity of their psychological effects. ${ }^{15}$ Both positive and negative change scores of the effects were used for the analysis. The Japanese version that was translated and validated by Nakai et $\mathrm{al}^{28}$ was used in this study.

\section{Interpersonal Sensitivity Measure (IPSM)}

The IPSM is a self-administered questionnaire with 36 items that measure sensitivity to others regarding aspects of interpersonal awareness (eg, "I worry about the effects I have on other people"), need for approval (eg, "I feel secure when I'm in a close relationship"), separation anxiety (eg, "I feel insecure when I say goodbye to people"), timidity (eg, "I avoid saying what I think for fear of being rejected"), and fragile inner-self (eg, "If others knew the real me, they would not like me"). ${ }^{29}$ The Japanese version established by Kuwabara et $\mathrm{al}^{30}$ was used in this study, and the mean score of all items was used for the analysis.

\section{Statistical Analysis}

To calculate correlation variables and differences between categorical variables, analysis using Pearson correlation coefficients and the Student's $t$-test, respectively, were performed using IBM SPSS Statistics for Windows Version. 25.0 (IBM Corp., Armonk, NY).

Stepwise multiple regression analysis (backward selection) was conducted with STAI-Y state anxiety as the dependent variable, and the following 14 items as independent variables: age, sex, current marital status, presence of offspring, living alone, education years, employment status, present physical illness, CATS subscores (neglect, punishment, and sexual abuse), LES (positive and negative) change score, and IPSM. As described in the Introduction section, covariance structure analysis with the robust maximum likelihood estimation method was performed using Mplus ver. 7.3. The comparative fit 
index (CFI) and Root Mean Square Error Approximation (RMSEA) were used as fit indices. A CFI of greater than 0.95 and a RMSEA of less than 0.08 were considered as an acceptable fit, whereas a CFI of greater than 0.97 and a RMSEA of less than 0.05 were regarded as a good fit in this study. ${ }^{28}$

A $P$-value of less than 0.05 was considered to indicate a statistically significant difference between groups.

\section{Results}

\section{Demographic Characteristics and Scores} of CATS, LES, IPSM, and STAI-Y State

\section{Anxiety}

Demographic information of the 404 subjects, as well as the means of their questionnaire scores are shown in Table 1. Each item's correlation coefficient with state anxiety, and differences in state anxiety between the categorical groups of each characteristic are also provided. Demographic characteristics were not associated with state anxiety. LES negative change scores, interpersonal sensitivity scores, and childhood maltreatment scores (neglect and total score) positively and significantly correlated with state anxiety. Positive change scores of LES negatively correlated with state anxiety. Only 2 participants reported comorbid psychiatric disorders; 1 participant had depression and the other had bipolar disorder (data not shown).

\section{Stepwise Multiple Regression Analysis Using STAI-Y State Anxiety Score as the Dependent Variable}

The results of this analysis are shown in Table 2. Of the 14 independent variables, the following 5 were identified to be statistically significant by the stepwise method: IPSM score, positive and negative change scores of LES, neglect

Table I Characteristics, STAI-Y (State Anxiety), CATS, LES, and IPSM Scores, and Their Correlations with or Effects on STAI-Y (State Anxiety) in 404 Adult Subjects

\begin{tabular}{|c|c|c|}
\hline Characteristic or Measure & $\begin{array}{l}\text { Number or } \\
\text { Mean } \pm \text { SD }\end{array}$ & $\begin{array}{l}\text { Correlation with STAI-Y (State Anxiety) Scores (r) or Effect on STAI-Y (State } \\
\text { Anxiety) Scores (Mean } \pm \text { SD, t-test) }\end{array}$ \\
\hline Age (years) & $42.3 \pm 11.9$ & $r=0.000, P=1.000$ \\
\hline Sex (men: women) & 220: 184 & Men $(40.4 \pm 10.1)$ vs women $(40.0 \pm 10.5), P=0.713$ (t-test) \\
\hline Years of education & $15.2 \pm 2.0$ & $r=-0.010, P=0.847$ \\
\hline $\begin{array}{l}\text { Employment status (employed: } \\
\text { nonemployed) }\end{array}$ & $341: 56$ & Employed $(40.6 \pm 10.2)$ vs nonemployed $(37.8 \pm \mathrm{II} . \mathrm{I}), P=0.057$ (t-test) \\
\hline $\begin{array}{l}\text { Present marital status } \\
\text { (married: unmarried) }\end{array}$ & 287: 114 & Married $(39.8 \pm 10.2)$ vs unmarried $(41.5 \pm 10.4), P=0.131$ (t-test) \\
\hline Presence of offspring (yes: no) & 270: 131 & Yes $(40.0 \pm 10.6)$ vs no $(40.8 \pm 9.7), P=0.442$ (t-test) \\
\hline Living alone (yes: no) & I0I: 295 & Yes $(41.2 \pm 10.8)$ vs no $(39.9 \pm 10.1), P=0.286$ (t-test) \\
\hline $\begin{array}{l}\text { Comorbidities of physical } \\
\text { disease (yes: no) }\end{array}$ & $81: 319$ & Yes $(41.3 \pm 10.1)$ vs no $(40.0 \pm 10.4), P=0.291$ (t-test) \\
\hline \multicolumn{3}{|l|}{ CATS (average score) } \\
\hline Sexual abuse & $0.04 \pm 0.22$ & $r=0.085, P=0.087$ \\
\hline Neglect & $0.61 \pm 0.58$ & $r=0.224, P<0.001 * *$ \\
\hline Punishment & $1.41 \pm 0.62$ & $r=0.066, P=0.185$ \\
\hline Total & $0.65 \pm 0.43$ & $r=0.200, P<0.00 I^{* *}$ \\
\hline IPSM (total) & $84.5 \pm 14.2$ & $r=0.333, P<0.00 I^{* *}$ \\
\hline \multicolumn{3}{|l|}{ LES (change score) } \\
\hline Negative & $1.7 \pm 3.1$ & $r=0.17 \mathrm{I}, P=0.00 \mathrm{I}^{* *}$ \\
\hline Positive & $1.7 \pm 3.0$ & $r=-0.160, P=0.001 * *$ \\
\hline
\end{tabular}

Notes: Data are presented as means \pm standard deviation $(\mathrm{SD})$ or numbers; $r=$ Pearson correlation coefficient; $* * P<0.0 \mathrm{I}$.

Abbreviations: STAI-Y, State-Trait Anxiety Inventory Form Y; CATS, Child Abuse and Trauma Scale; IPSM, Interpersonal Sensitivity Measure; LES, Life Experiences Survey. 
Table 2 Results of Stepwise Multiple Regression Analysis of STAI-Y State Anxiety Score

\begin{tabular}{|l|l|l|l|}
\hline Independent Factors Selected by Stepwise Regression & $\begin{array}{l}\text { Standardized Partial Regression } \\
\text { Coefficient (Beta) }\end{array}$ & P-value \\
\hline IPSM score & 0.296 & $<0.001$ & 1.162 \\
LES positive & -0.176 & $<0.001$ & 1.025 \\
CATS (neglect) & 0.130 & 0.010 & 1.138 \\
Employment status (nonemployed = 0, employed = I) & 0.121 & 0.012 & 1.038 \\
LES (negative) & 0.100 & 0.043 & 1.087 \\
\hline Adjusted $R^{2}=0.165$ & $F=15.858, P<0.001$ & & \\
\hline
\end{tabular}

Notes: Dependent variable: STAI-Y state anxiety score. The 14 independent variables tested: age, sex $($ men $=0$, women $=1$ ), current marital status $($ unmarried $=0$, married $=I$ ), presence of offspring (yes $=I$, no $=0$ ), living alone (yes $=0$, no $=1$ ), years of education, employment status (nonemployed $=0$, employed $=I$ ), comorbidity of physical disease (yes = I, no =0), CATS (neglect, punishment, and sexual abuse), LES (positive and negative change), and IPSM. $R^{2}=$ square sum of the multiple correlation coefficient. Abbreviations: VIF, variance inflation factor; IPSM, Interpersonal Sensitivity Measure; CATS, Child Abuse and Trauma Scale; STAI-Y, State-Trait Anxiety Inventory Form Y; LES, Life Experiences Survey.

scores of CATS, and employment status. The adjusted $R^{2}$ of this model was 0.165 . The variance inflation factors in the model were calculated to range from 1.025 to 1.162 , and were considered to be negative for multicollinearity.

\section{Correlations Between CATS Scores, LES Scores, and IPSM Scores}

Table 3 shows the correlations between CATS scores, LES scores, and IPSM scores. IPSM scores significantly positively correlated with CATS total scores, neglect subscores, and negative change scores of the LES. Negative change scores of the LES significantly positively correlated with CATS total scores, sexual abuse and neglect subscores, IPSM scores, and positive change scores of the LES. Positive change scores of the LES were not correlated with CATS scores or IPSM scores.

\section{Analysis of the Structural Equation Model}

Covariance structure analysis was conducted using the structural equation model shown in Figure 1. The latent variable of childhood maltreatment was derived from the 3 observed variables of CATS (neglect, punishment, and sexual abuse). In this model, the goodness of fit was good or acceptable: RMSEA $=0.046$ and CFI $=0.961$. The $R^{2}$ for state anxiety in this model was 0.172 , indicating that this model explains $17.2 \%$ of the variability in state anxiety scores.

\section{Direct Effects}

Six statistically significant direct effects were identified using this model. The following 3 variables had statistically significant positive direct effects on state anxiety: childhood maltreatment, LES negative change score, and interpersonal sensitivity (IPSM score). In addition, LES positive change score was found to have a negative effect on state anxiety, childhood maltreatment had a positive direct effect on interpersonal sensitivity, and interpersonal sensitivity had a positive effect on LES negative change score.

\section{Indirect Effects}

Nine indirect effects were analyzed, and the following 3 indirect effects were found to be statistically significant.

Table 3 Correlation ( $r$ ) Between Subscale Scores of the CATS, LES Positive and Negative Scores, and IPSM Scores

\begin{tabular}{|l|l|l|l|l|l|l|l|}
\hline & $\begin{array}{l}\text { CATS } \\
\text { (Neglect) }\end{array}$ & $\begin{array}{l}\text { CATS } \\
\text { (Punishment) }\end{array}$ & $\begin{array}{l}\text { CATS (Sexual } \\
\text { Abuse) }\end{array}$ & $\begin{array}{l}\text { CATS } \\
\text { (Total) }\end{array}$ & $\begin{array}{l}\text { LES } \\
\text { (Positive) }\end{array}$ & $\begin{array}{l}\text { LES } \\
\text { (Negative) }\end{array}$ & $\begin{array}{l}\text { IPSM } \\
\text { CATS (neglect) }\end{array}$ \\
CATS (punishment) & 1.000 & $0.421^{* *}$ & $0.328^{* *}$ & $0.924^{* *}$ & -0.016 & $0.122^{*}$ & $0.306^{*}$ \\
CATS (sexual abuse) & & 1.000 & $0.183^{* *}$ & $0.644^{* *}$ & -0.087 & 0.076 & 0.056 \\
CATS (total) & & 1.000 & $0.421^{* *}$ & 0.023 & $0.116^{*}$ & 0.009 \\
LES (positive) & & & & 1.000 & -0.011 & $0.124^{*}$ & $0.268^{* *}$ \\
LES (negative) & & & & 1.000 & $0.135^{* *}$ & 0.036 \\
IPSM & & & & & & & \\
\hline
\end{tabular}

Notes: $r=$ Pearson correlation coefficient; $* P<0.05, * * P<0.01$.

Abbreviations: CATS, Child Abuse and Trauma Scale; LES, Life Experiences Survey; IPSM, Interpersonal Sensitivity Measure. 


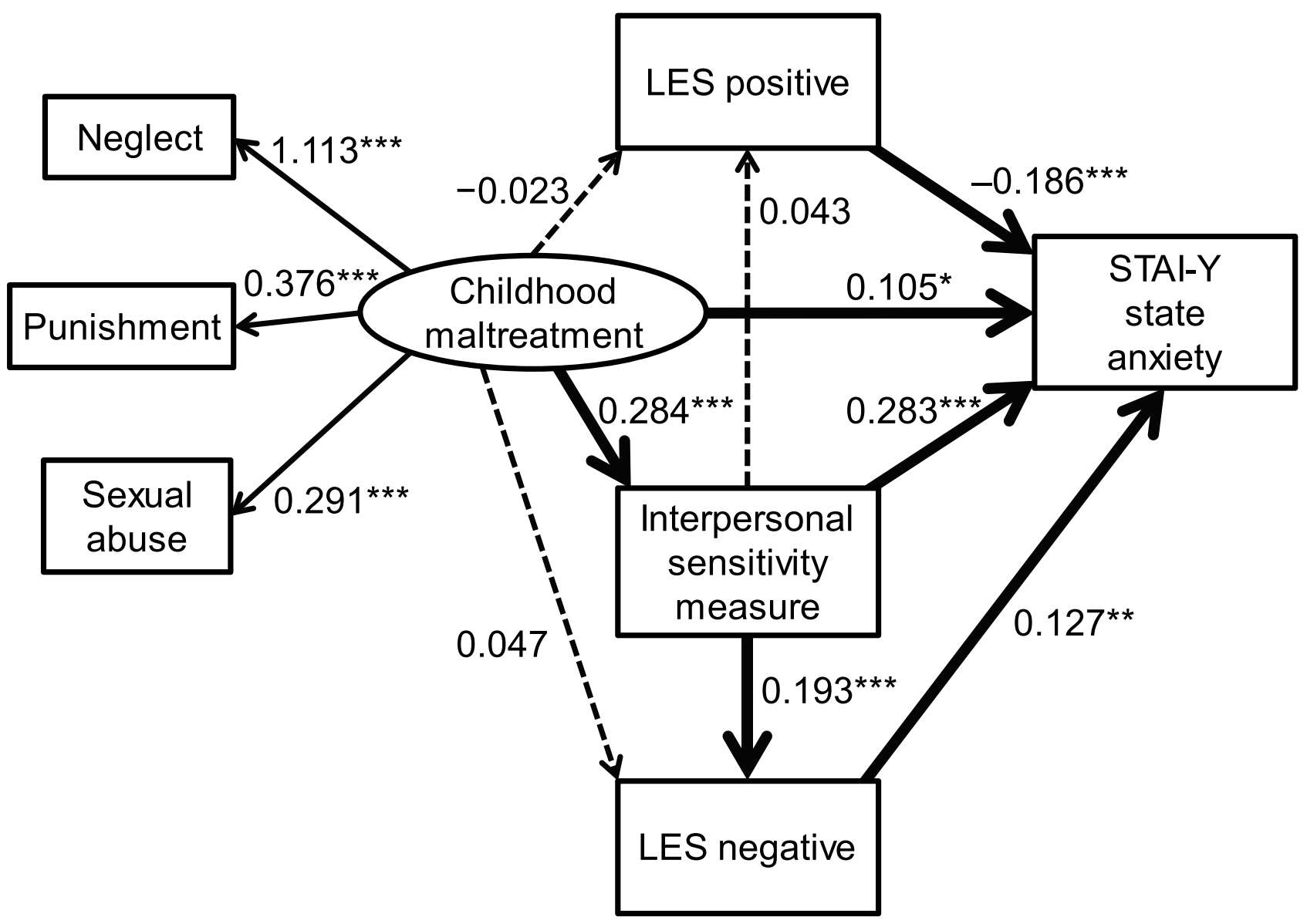

Figure I A structural equation model built based on the hypothesis of this study. The model consists of childhood maltreatment, positive and negative evaluations of life events (LES positive and negative change scores), interpersonal sensitivity (Interpersonal Sensitivity Measure, IPSM), and state anxiety (STAI-Y state anxiety). Rectangles represent observed variables and the oval represents the latent variable. Arrows with solid lines indicate statistically significant pathways. Arrows with broken lines indicate statistically nonsignificant pathways. Numbers next to the arrows are the standardized path coefficients $(-\mathrm{I} \leq$ beta $\leq \mathrm{I})$. $* P<0.05$, $* * P<0.0 \mathrm{I}$, $* * * P<0.00 \mathrm{I}$.

Abbreviations: LES, Life Experiences Survey; STAI-Y, State-Trait Anxiety Inventory Form Y.

Interpersonal sensitivity mediated the effects of childhood maltreatment on state anxiety (standardized correlation coefficient: $0.080, P<0.001$ ), LES negative change score mediated the effects of interpersonal sensitivity on state anxiety (standardized correlation coefficient: 0.024 , $P=0.048$ ), and interpersonal sensitivity mediated the effects of childhood maltreatment on LES negative change score (standardized correlation coefficient: $0.055, P=$ $0.001)$.

In contrast, the following 6 indirect effects were not statistically significant: the mediating effects of LES negative change score on the effects of childhood maltreatment on state anxiety (standardized correlation coefficient: $0.006, P=0.473$ ), the mediating effects of LES positive change score on the effects of childhood maltreatment on state anxiety (standardized correlation coefficient: 0.004, $P=0.687$ ), the mediating effects of interpersonal sensitivity with LES positive change score on the effects of childhood maltreatment on state anxiety (standardized correlation coefficient: $-0.002, P=0.461$ ), the mediating effects of interpersonal sensitivity with LES negative change score on the effects of childhood maltreatment on state anxiety (standardized correlation coefficient: 0.007 , $P=0.059$ ), the mediating effects of interpersonal sensitivity on the effects of childhood maltreatment on LES positive change score (standardized correlation coefficient: 0.012, $P=0.459$ ), and the mediating effects of LES positive change score on the effects of interpersonal sensitivity on state anxiety (standardized correlation coefficient: $-0.008, P=0.459$ ).

\section{Discussion}

In this study, analysis using a structural equation model showed that the experience of maltreatment in childhood increased state anxiety in adulthood both directly and indirectly via its effects on interpersonal sensitivity. 
Similar to this finding, we previously reported that interpersonal sensitivity mediates the effects of childhood maltreatment on depressive symptoms in adult community volunteers. ${ }^{13}$ Our present study also showed that the negative evaluation of life events in the previous year mediates the effects of interpersonal sensitivity on anxiety symptoms, and that interpersonal sensitivity mediates the effects of childhood maltreatment on the negative evaluation of life events. To our knowledge, this study is the first to demonstrate that interpersonal sensitivity mediates the effects of childhood maltreatment on state anxiety and the negative evaluation of life events in adulthood.

As mentioned in the Introduction section, childhood maltreatment is associated with anxiety disorders and anxiety symptoms, ${ }^{5}$ as well as interpersonal sensitivity, ${ }^{13}$ and interpersonal sensitivity is associated with anxiety symptoms. ${ }^{14}$ Whereas inter-associations among these 3 factors are expected, it is important that we confirmed their simultaneous association in the present study. Therefore, these associations suggest the following psychological flow: adverse childhood stress negatively affects interpersonal relationships, induces social maladjustment, and finally worsens anxiety symptoms in adulthood. Supporting this idea, the negative evaluation of life events in adolescence, which may be associated with social maladjustment, is reportedly a risk factor for anxiety disorders. ${ }^{31}$ The results of covariance structure analysis in the present study also suggest that maladjustment as expressed by the negative evaluation of life events in adulthood may be more likely to develop in people with a background of childhood maltreatment and interpersonal sensitivity.

Our previous study demonstrated that the negative evaluation of life events mediates the effects of neuroticism on depressive symptoms in adult volunteers, and that neuroticism mediates the effects of childhood maltreatment on the negative evaluation of life events. ${ }^{21}$ These results are similar to those of our present study regarding the association between the negative evaluation of life events, interpersonal sensitivity, and anxiety symptoms. Although neuroticism and interpersonal sensitivity are considered to be distinct personality traits, they are moderately associated with each other, and some subitems of interpersonal sensitivity are specifically associated with neuroticism. ${ }^{29}$ A stress-sensitive characteristic common to interpersonal sensitivity and neuroticism may be closely associated with the link between childhood maltreatment and the negative evaluation of life events.
The present study was conducted in adult volunteers from the community, which limits the applicability of the results to patients with anxiety disorders in the clinical setting. However, regarding the clinical treatment of anxiety disorders, our results indicate that childhood maltreatment and interpersonal sensitivity may be involved in the pathogenesis of anxiety symptoms. ${ }^{32}$ A study of the effects of pharmacotherapy in patients with social anxiety disorder who have a history of childhood maltreatment demonstrated higher dropout rates for patients with a history of emotional or physical abuse, as well as a slower onset of medication efficacy in emotionally abused patients. ${ }^{33}$ These results suggest that the screening of patients with a history of childhood maltreatment should also be considered before pharmacotherapy. Moreover, interpersonal sensitivity was found to correlate with anxiety symptoms and quality of life in patients with social anxiety disorder, ${ }^{14}$ and furthermore, interpersonal sensitivity and maladaptive interpersonal beliefs in patients with anxiety disorder can be improved by cognitive behavioral therapy. ${ }^{34}$ Thus, the assessment of interpersonal sensitivity is also useful for understanding and treating patients with anxiety disorders. From the above information, interpersonal psychotherapy may be an option for the treatment of anxiety symptoms and anxiety disorders. Although interpersonal psychotherapy is reportedly effective for treating anxiety disorders, the higher efficacy of this therapy than other psychological interventions, such as cognitive behavioral therapy, has not yet been reported. ${ }^{35}$ In a pilot study comparing the efficacy of interpersonal therapy and supportive therapy for patients with social anxiety disorder, improvements in anxiety symptoms were found in both groups. ${ }^{36}$ The efficacy of interpersonal therapy to treat high levels of concern regarding negative evaluations from others has been reported; however, no statistically significant differences were observed between therapies regarding the proportion of respondents of the anxiety symptoms. ${ }^{36}$ As the level of concern regarding negative evaluations from others was improved by interpersonal therapy in previous clinical trials, ${ }^{36}$ the evaluation of interpersonal sensitivity in patients with anxiety disorders may enable doctors to select therapies that are tailored to each patient's characteristics, and to more accurately evaluate therapeutic effectiveness.

A patient or client's history of childhood maltreatment is not only unmodifiable but can often have negative effects upon even just the brief recollection of memories. In general practice, a patient or client's history of childhood 
maltreatment is often not addressed at the beginning of treatment. However, as treatment progresses, the history of childhood maltreatment may need to be considered by therapists. At that time, interpersonal sensitivity can be assessed and targeted by therapists to improve anxiety symptoms without mentioning the invasive memories. The subsequent improvement of anxiety symptoms will help to build a healthy doctor-patient relationship, which will eventually provide clues towards effective interventions for the traumatic childhood experiences. Further prospective studies on patients with and without a history of childhood maltreatment should be performed in the future.

There are several limitations to this study. First, there may be recall bias owing to the self-administered survey and the memory of respondents might be uncertain. Secondly, as the survey had a response rate of less than $50 \%$, respondents may not represent the general population. Finally, although an association among the factors in the structural equation model is assumed from the association of their time of occurrence, a causal association among the factors cannot be confirmed owing to the crosssectional design of this study. Therefore, future validation through prospective research is necessary to establish a causal association among childhood maltreatment, interpersonal sensitivity, and anxiety in adulthood. Finally, this study was conducted in adult volunteers from the community, and its applicability and generalizability to patients with anxiety disorders remains unclear.

\section{Conclusion}

Effects of the experience of maltreatment in childhood on state anxiety in adulthood were found to not only be direct but to also be mediated by interpersonal sensitivity. These results suggest that assessing interpersonal sensitivity in the treatment of patients with a history of childhood maltreatment may be useful in understanding the psychology and psychopathology of their anxiety.

\section{Acknowledgments}

We thank Dr. Helena Popiel of the Department of International Medical Communications, Tokyo Medical University, for editorial review of the manuscript.

\section{Author Contributions}

All authors made substantial contributions to the conception and design of the study, acquisition of data, or analysis and interpretation of data; took part in drafting the manuscript or revising it critically for important intellectual content; gave final approval of the version to be published; and agree to be accountable for all aspects of the work.

\section{Disclosure}

Hiroshi Nakazawa has been an employee of Pfizer Japan, Inc. Jiro Masuya has received personal compensation from Otsuka Pharmaceutical, Eli Lilly, Astellas, and Meiji Yasuda Mental Health Foundation, and grants from Pfizer. Ichiro Kusumi has received personal compensation from Astellas, Chugai Pharmaceutical, Daiichi Sankyo, Dainippon Sumitomo Pharma, Eisai, Eli Lilly, Janssen Pharmaceutical, Kyowa Hakko Kirin, Meiji Seika Pharma, MSD, Nippon Chemiphar, Novartis Pharma, Ono Pharmaceutical, Otsuka Pharmaceutical, Pfizer, Tanabe Mitsubishi Pharma, Shionogi, and Yoshitomiyakuhin, and has received research grants from AbbVie GK, Asahi Kasei Pharma, Astellas, Boehringer Ingelheim, Chugai Pharmaceutical, Daiichi Sankyo, Dainippon Sumitomo Pharma, Eisai, Eli Lilly, GlaxoSmithKline, Kyowa Hakko Kirin, Meiji Seika Pharma, MSD, Novartis Pharma, Ono Pharmaceutical, Otsuka Pharmaceutical, Pfizer, Takeda Pharmaceutical, Tanabe Mitsubishi Pharma, Shionogi, and Yoshitomiyakuhin, and is a member of the advisory board of Dainippon Sumitomo Pharma and Tanabe Mitsubishi Pharma. Takeshi Inoue has received personal fees from Mochida Pharmaceutical, Takeda Pharmaceutical, Eli Lilly, Janssen Pharmaceutical, MSD, Taisho Toyama Pharmaceutical, Yoshitomiyakuhin, and Daiichi Sankyo; grants from Shionogi, Astellas, Tsumura, and Eisai; and grants and personal fees from Otsuka Pharmaceutical, Dainippon Sumitomo Pharma, Mitsubishi Tanabe Pharma, Kyowa Pharmaceutical Industry, Pfizer, Novartis Pharma, and Meiji Seika Pharma; and is a member of the advisory boards of Pfizer, Novartis Pharma, and Mitsubishi Tanabe Pharma. Masahiko Ichiki has received personal fees from Otsuka Pharmaceutical, Pfizer, Eli Lilly, Mitsubishi Tanabe Pharma, Mochida Pharmaceutical, Meiji Seika Pharma, Janssen Pharmaceutical, Takeda Pharmaceutical Company, MSD, Dainippon Sumitomo Pharma, and Eisai; grants from Otsuka Pharmaceutical, Eli Lilly, Eisai, Shionogi, Takeda Pharmaceutical, MSD, and Pfizer; and is a member of the advisory board of Meiji Seika Pharma. The other authors declare that they have no actual or potential conflicts of interest associated with this study.

\section{References}

1. Serafini G, Canepa G, Adavastro G, et al. The relationship between childhood maltreatment and non-suicidal self-injury: a systematic review. Front Psychiatry. 2017;8. doi:10.3389/fpsyt.2017.00149 
2. Serafini G, Gonda X, Pompili M, Rihmer Z, Amore M, Engel-Yeger B. The relationship between sensory processing patterns, alexithymia, traumatic childhood experiences, and quality of life among patients with unipolar and bipolar disorders. Child Abuse Negl. 2016;62:39-50. doi:10.1016/j.chiabu.2016.09.013

3. Heim C, NemeroffCB. The role of childhood trauma in the neurobiology of mood and anxiety disorders: preclinical and clinical studies. Biol Psychiatry. 2001;49(12):1023-1039. doi:10.1016/S0006-3223(01)01157-X

4. De Graaf R, Bijl RV, Smit F, Vollebergh WAM, Spijker J. Risk factors for 12-month comorbidity of mood, anxiety, and substance use disorders: findings from the Netherlands Mental Health Survey and Incidence Study. Am J Psychiatry. 2002;159(4):620-629. doi:10.1176/appi.ajp.159.4.620

5. Lindert J, Von Ehrenstein OS, Grashow R, Gal G, Braehler E, Weisskopf MG. Sexual and physical abuse in childhood is associated with depression and anxiety over the life course: systematic review and meta-analysis. Int $J$ Public Health. 2014;59(2):359-372. doi:10.1007/s00038-013-0519-5

6. Li M, D'Arcy C, Meng X. Maltreatment in childhood substantially increases the risk of adult depression and anxiety in prospective cohort studies: systematic review, meta-analysis, and proportional attributable fractions. Psychol Med. 2016;46(4):717-730. doi:10.1017/S0033291715002743

7. Rapsey CM, Scott KM, Patterson T. Childhood sexual abuse, poly-victimization and internalizing disorders across adulthood and older age: findings from a 25-year longitudinal study. J Affect Disord. 2019;244:171-179. doi:10.1016/j.jad.2018.10.095

8. Raposo SM, Mackenzie CS, Henriksen CA, Afifi TO. Time does not heal all wounds: older adults who experienced childhood adversities have higher odds of mood, anxiety, and personality disorders. Am J Geriatr Psychiatry. 2014;22(11):1241-1250. doi:10.1016/j.jagp.2013.04.009

9. Huh HJ, Kim KH, Lee HK, Chae JH. The relationship between childhood trauma and the severity of adulthood depression and anxiety symptoms in a clinical sample: the mediating role of cognitive emotion regulation strategies. J Affect Disord. 2017;213:44-50. doi:10.1016/j.jad.2017.02.009

10. Estévez A, Jauregui P, Ozerinjauregi N, Herrero-Fernández D. The role of early maladaptive schemas in the appearance of psychological symptomatology in adult women victims of child abuse. J Child Sex Abus. 2017;26(8):889-909. doi:10.1080/10538712.2017.1365318

11. Cantón-Cortés D, Cortés MR, Cantón J. Pathways from childhood sexual abuse to trait anxiety. Child Abus Negl. 2019;97:104148. doi:10.1016/j.chiabu.2019.104148

12. Widom CS, Czaja SJ, Kozakowski SS, Chauhan P. Does adult attachment style mediate the relationship between childhood maltreatment and mental and physical health outcomes? Child Abus Negl. 2018;76:533-545. doi:10.1016/j.chiabu.2017.05.002

13. Otsuka A, Takaesu Y, Sato M, et al. Interpersonal sensitivity mediates the effects of child abuse and affective temperaments on depressive symptoms in the general adult population. Neuropsychiatr Dis Treat. 2017;13:2559-2568. doi:10.2147/NDT.S144788

14. Harb GC, Heimberg RG, Fresco DM, Schneier FR, Liebowitz MR. The psychometric properties of the interpersonal sensitivity measure in social anxiety disorder. Behav Res Ther. 2002;40(8):961-979. doi:10.1016/S0005-7967(01)00125-5

15. Sarason IG, Johnson JH, Siegel JM. Assessing the impact of life changes: development of the life experiences survey. J Consult Clin Psychol. 1978;46(5):932-946. doi:10.1037//0022-006x.46.5.932

16. Liu RT, Choi JY, Boland EM, Mastin BM, Alloy LB. Childhood abuse and stress generation: the mediational effect of depressogenic cognitive styles. Psychiatry Res. 2013;206(2-3):217-222. doi:10.1016/j.psychres.2012.12.001

17. Kaiser RH, Clegg R, Goer F, et al. Childhood stress, grown-up brain networks: corticolimbic correlates of threat-related early life stress and adult stress response. Psychol Med. 2018;48(7):1157-1166. doi: $10.1017 / \mathrm{s} 0033291717002628$
18. Duijndam S, Karreman A, Denollet J, Kupper N. Physiological and emotional responses to evaluative stress in socially inhibited young adults. Biol Psychol. 2020;149:107811. doi:10.1016/j.biopsycho. 2019.107811

19. Shahar B, Doron G, Szepsenwol O. Childhood maltreatment, shame-proneness and self-criticism in social anxiety disorder: a sequential mediational model. Clin Psychol Psychother. 2015;22 (6):570-579. doi:10.1002/cpp.1918

20. Kanai Y, Takaesu Y, Nakai Y, et al. The influence of childhood abuse, adult life events, and affective temperaments on the well-being of the general, nonclinical adult population. Neuropsychiatr Dis Treat. 2016;12:823-832. doi:10.2147/NDT.S100474

21. Ono K, Takaesu Y, Nakai Y, et al. Associations among depressive symptoms, childhood abuse, neuroticism, and adult stressful life events in the general adult population. Neuropsychiatr Dis Treat. 2017;13:477-482. doi:10.2147/NDT.S128557

22. Ono Y, Takaesu Y, Nakai Y, et al. The influence of parental care and overprotection, neuroticism and adult stressful life events on depressive symptoms in the general adult population. $J$ Affect Disord. 2017;217:66-72. doi:10.1016/j.jad.2017.03.058

23. World Medical Association. World Medical Association declaration of Helsinki: ethical principles for medical research involving human subjects. JAMA. 2013;310(20):2191. doi:10.1001/jama.2013.281053

24. Spielberger C. Manual for the State-Trait Inventory STAI (Form Y). Palo Alto, CA: Mind Garden; 1983.

25. Hidano N, Fukuhara M, Iwawaki M, Soga S, Spielberger C. StateTrait Anxiety Inventory-Form JYZ; 2000.

26. Sanders B, Becker-Lausen E. The measurement of psychological maltreatment: early data on the child abuse and trauma scale. Child Abus Negl. 1995;19(3):315-323. doi:10.1016/S0145-2134(94)00131-6

27. Tanabe H, Ozawa S, Goto K. Psychometric properties of the Japanese version of the Child Abuse and Trauma Scale (CATS). In: The 9th Annual Meeting of the Japanese Society for Traumatic Stress Studies; 2010.

28. Nakai Y, Inoue T, Toda H, et al. The influence of childhood abuse, adult stressful life events and temperaments on depressive symptoms in the nonclinical general adult population. $J$ Affect Disord. 2014;158:101-107. doi:10.1016/j.jad.2014.02.004

29. Boyce P, Parker G. Development of a scale to measure interpersonal sensitivity. Aust N Z J Psychiatry. 1989;23(3):341-351. doi:10.1177/ 000486748902300320

30. Kuwabara H, Sakado K, Uehara T, Sakado M, Sato TST. The Japanese version of interpersonal sensitivity measure: its reliability and validity (in Japanese). Arch Psychiatr Diagnostics Clin Eval. 1999;10:333-341.

31. Espejo EP, Hammen C, Brennan PA. Elevated appraisals of the negative impact of naturally occurring life events: a risk factor for depressive and anxiety disorders. J Abnorm Child Psychol. 2012;40 (2):303-315. doi:10.1007/s10802-011-9552-0

32. Read J, Hammersley P, Rudegeair T. Why, when and how to ask about childhood abuse. Adv Psychiatr Treat. 2007;13(2):101-110. doi:10.1192/apt.bp.106.002840

33. Bruce LC, Heimberg RG, Blanco C, Schneier FR, Liebowitz MR. Childhood maltreatment and social anxiety disorder: implications for symptom severity and response to pharmacotherapy. Depress Anxiety. 2012;29(2):132-139. doi:10.1002/da.20909

34. Boden MT, John OP, Goldin PR, Werner K, Heimberg RG, Gross JJ. The role of maladaptive beliefs in cognitive-behavioral therapy: evidence from social anxiety disorder. Behav Res Ther. 2012;50 (5):287-291. doi:10.1016/j.brat.2012.02.007

35. Markowitz JC, Lipsitz J, Milrod BL. Critical review of outcome research on interpersonal psychotherapy for anxiety disorders. Depress Anxiety. 2014;31(4):316-325. doi:10.1002/da.22238

36. Lipsitz JD, Gur M, Vermes D, et al. A randomized trial of interpersonal therapy versus supportive therapy for social anxiety disorder. Depress Anxiety. 2008;25(6):542-553. doi:10.1002/da.20364 


\section{Publish your work in this journal}

Neuropsychiatric Disease and Treatment is an international, peerreviewed journal of clinical therapeutics and pharmacology focusing on concise rapid reporting of clinical or pre-clinical studies on a range of neuropsychiatric and neurological disorders. This journal is indexed on PubMed Central, the 'PsycINFO' database and CAS, and is the official journal of The International Neuropsychiatric Association (INA). The manuscript management system is completely online and includes a very quick and fair peer-review system which is all easy to use. Visit http://www.dovepress.com/testimonials.php to read real quotes from published authors.

Submit your manuscript here: https://www.dovepress.com/neuropsychiatric-disease-and-treatment-journal 